\title{
PREVALENCE OF ANAPLASMOSIS IN CATTLE IN SIRAJGANJ DISTRICT OF BANGLADESH
}

\section{SM Shariful Hoque Belal ${ }^{1}$, Md. Abdullah-Al-MAHMUD ${ }^{2 *}$ and Mst. Jannatul Ferdous $^{3}$}

${ }^{1}$ Veterinary Surgeon, District Veterinary Hospital, Sirajganj, ${ }^{2}$ Additional Veterinary Surgeon, Upazila Livestock Office, Ullapara, Sirajganj, ${ }^{3}$ Medical Officer, Gandhail Union Sub Centre, Kazipur, Sirajganj, Bangladesh

*Corresponding author: Md. Abdullah-Al-Mahmud, e-mail: dr.mahmud04@gmail.com

\section{ARTICLE INFO}

\section{ABSTRACT}

An epidemiological investigation was conducted to ascertain the prevalence of anaplasmosis in cattle in Sirajganj district of Bangladesh, during the period of December 2013 to November 2014. During one year study period a total of 395 cattle were examined, and where 102 were found to be infected with Anaplasma spp. On Geimsa stained blood smear examination, it was observed that the overall prevalence of anaplasmosis in cattle was recorded as $25.82 \%$. The effect of area, age, sex, breed and season was observed in cattle during this study. The highest prevalence (34.19\%) was reported in the older cattle ( $>3$ years of age) and the prevalence was higher in female (28.88\%) than male (19.20\%). All crossbred cattle was showed higher prevalence than local cattle. The prevalence of anaplasmosis infection was noticed as the highest in the rainy season $(30.68 \%)$ in relation to summer $(27.50 \%)$ and winter $(15.15 \%)$ season. From the study it was evident that cattle were infected with the organism and caused a serious economic loss which will assist to take necessary preventive interventions.

To cite this article: SMSH Belal, MAA Mahmud and MJ Ferdous, 2014. Prevalence of anaplasmosis in cattle in Sirajganj district of Bangladesh. Res. Agric., Livest. Fish. 1(1): 97-103.

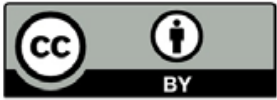

This article is an open access article licensed under the terms of the Creative Commons Attribution License.

www.agroaid-bd.org/ralf, e-mail: editor.ralf@gmail.com 


\section{INTRODUCTION}

Anaplasmosis is an infectious tick-borne disease of ruminants caused by obligate intraerythrocytic rickettsia organism of the genus Anaplasma and characterized clinically by fever, inappetance, decrease milk yield, progressive anaemia, icterus, brownish urine, pale mucous membrane, labored breathing and constipation. It is common in tropical and subtropical country and sporadic in temperate region. Bangladesh is usually hot and humid except in winter, and the climatic condition of Bangladesh is very conducive to a wide variety of parasites as well as ticks (Razzak and Shaikh, 1969) which have been recognized as the notorious threat due to severe irritation, allergy and toxicosis (Niyonzema and Kiltz, 1986). Tick-borne diseases cause substantial losses to the livestock industry throughout the world (Ananda et al., 2009; Kakarsulemankhel, 2011) as these have got a serious economic impact due to obvious reason of death, decreased productivity, lowered working efficiency (Uilenberg, 1995), increased cost for control measures (Makala et al., 2003) and limited introduction of genetically improved cattle in an area (Radostits et al., 2000). There are many Anaplasma species but, Anaplasma marginale is the most important one (Kumar et al., 2010). Prevalence of blood rickettsia like A. marginale, A. centrale have been reported in animals of Bangladesh (Ahmed, 1976; Samad and Gautam, 1984).

Anaplasmosis are the more prevalent in different areas of Bangladesh where Chowdhury et al. (2006) recorded $70 \%$ anaplasmosis in Sirajganj district. Talukdar and Karim (2001) also documented higher prevalence (33\%) of anaplasmosis in Baghabari Milk Shed Area, Sirajganj. Kamani (2010) and Kocan et al. (2003) was observed that the prevalence of anaplasmosis was higher in adult than young cattle. Breed and seasonal variation on anaplasma infection was reported by Ananda et al. (2009) and Radostits et al. (2000). Sirajganj is the most important dairy belt area of Bangladesh and the density of cattle population of this district is high. The climatic condition and geographical location of the areas might favor the growth and multiplication of ticks which act as natural vectors of anaplasmosis and that causes one of the major veterinary problems affecting livestock industries. Considering the above situations, the present research was undertaken to know the prevalence of anaplasmosis in cattle in Sirajganj district of Bangladesh.

\section{MATERIALS AND METHODS}

\section{Geographical location of study area}

Sirajganj district is situated in Rajshahi Division, Bangladesh; its geographical coordinates are $24^{\circ} 27^{\prime} 0^{\prime \prime}$ North, $89^{\circ} 43^{\prime} 0^{\prime \prime}$ East. Sirajganj has an area of 2,498 sq.km (964 sq miles) including riverine areas, and it represents around 1.7 percent of the total area of Bangladesh. It ranks $3^{\text {rd }}$ in size among the eight districts of Rajshahi division and $25^{\text {th }}$ among the 64 districts of Bangladesh. It contains 9 upazilas namely Sirajganj Sadar, Shahjadpur, Ullapara, Kamarkhand, Belkuchi, Chouhali, Raigonj, Tarash and Kazipur.The annual average temperature of the district reaches a maximum of $34.6^{\circ} \mathrm{C}$, and a minimum of $11.9^{\circ} \mathrm{C}$. The annual rainfall is $1610 \mathrm{~mm}(63.4 \mathrm{in})$.

\section{Experimental animals and duration of study}

This research work was conducted at the Field Diseases Investigation Laboratory (FDIL), Sirajganj on the clinical cases in cattle during the period from December 2013 to November 2014. During one year study period, a total of 395 case of sick and suspected cattle were studied actively that was informed by owner of the patient, Veterinary Field Assistant, Veterinary Surgeon and Upazila Livestock Officer of respective upazila of Sirajganj district. Only 102 cattle were infected by Anaplasma spp among 395 suspected cases. Date, age, sex, breed and complaint of the owner of all studied animal were noted in the registered book of the FDIL, Sirajganj. 


\section{Methods followed for diagnosis}

The history and physical examination of each of the patient was carried out for the cattle for diagnosis of Anaplasmosis.

\section{History taking}

History of patient like (a) Date of examination, (b) Signalment (client and patient) identification, (c) Chief complaint, (d) Patient illness, (e) Past medical history were included. In addition, the complete medical history like (a) Family medical history, (b) Vaccination history, (c) Travel history, (d) Diet history, (f) Environmental history, (g) Birth history (h) Potential source of intoxication were investigated.

\section{Physical examination}

Physical examination was done by visual inspection, pulse and respiration rate and rectal temperature. Examination of the different organs and systems of the body was carried out by using the clinical methods of palpation, percussion and auscultation.

\section{Sample collection and Examination}

3-5 $\mathrm{ml}$ blood samples were collected from the jugular vein of the clinically suspected animals in EDTA containing vacutainers and transported to FDIL, Sirajganj in ice bags for microscopic examination following the method of Adam, Paul and Zaman. Briefly, a thin blood smear was prepared from each blood sample, air dried and fixed in methanol for 2-3 minutes. Staining was done in 5\% Giemsa's stain and rinsing was performed in two changes of distilled water buffered to $\mathrm{pH} 7.2$, then examined under microscope (100x) with immersion oil for the identification of blood parasites as described by Soulsby (1982).

\section{Statistical analysis}

Data were entered in Microsoft Excel 2007 and transferred to R 2.14.2 (The R Foundation for Statistical Computing, Vienna, Austria). Descriptive statistics were obtained using Data Mining package of the software R 2.14.2.

\section{RESULTS AND DISCUSSION}

\section{Overall prevalence of anaplasmosis in cattle}

Distribution of anaplasmosis in cattle in different areas of Sirajganj district is shown in Table 1. The overall prevalence of anplasmosis in Sirajganj district was $25.82 \%$, but the prevalence was found to vary significantly in different upazilas. The highest rate was reported in Shahjadpur upazila $(31.42 \%)$ and the lowest was found in Chouhali (14.28\%). In case of other upazilas the prevalence of the disease was observed $29.16 \%, 25.86 \%, 25.53 \%, 23.33 \%, 18.18 \%, 17.39 \%$ and $16.66 \%$ in Ullapara, Belkuchi, Sirajganj Sadar, Kamarkhand, Tarash, Kazipur and Raygonj respectively. The prevalence obtained in this study was found relating to the stock density in different upazila (Report of DLS and statistical pocketbook, 2011). High number of cattle population with tick population, high number of lowland/ flood plain based area/ ponds and veterinary practitioners in Shahjadpur upazila favored the transmission of organism among animals probably causing high prevalence. The present study supports the earlier report of Anaplasma infection in Bangladesh (Talukdar et al., 2001) who was observed that the prevalence of anaplasmosis in cattle was $33 \%$ in Baghabari (Shahjadpur) Milk Shed Area. The occurrence of subclinical Anaplasma infection in 5.93\% cattle has been reported from Bangladesh (Samad et al., 1989). The present study also support with the report of Arunkumar et al. (2013) who observed that the overall prevalence rate of $A$. marginale infection was $19.3 \%$ in Chennai district of Tamil Nadu in India. 
Table 1. Distribution of anaplasmosis in cattle in different areas of Sirajganj district

\begin{tabular}{|lccc|}
\hline Upazila & No. of cattle tested & No. of positive case & Prevalence (\%) \\
\hline Sirajganj Sadar & 47 & 12 & 25.53 \\
Shahjadpur & 105 & 33 & 31.42 \\
Ullapara & 72 & 21 & 29.16 \\
Belkuchi & 58 & 15 & 25.86 \\
Kamarkhand & 30 & 7 & 23.33 \\
Raygonj & 24 & 4 & 16.66 \\
Tarash & 22 & 4 & 18.18 \\
Kazipur & 23 & 4 & 17.39 \\
Chouhali & 14 & 2 & 14.28 \\
\hline Overall & $\mathbf{3 9 5}$ & $\mathbf{1 0 2}$ & $\mathbf{2 5 . 8 2}$ \\
\hline
\end{tabular}

\section{Age-wise prevalence}

Age-wise prevalence of anaplasmosis in cattle is shown in table 2. Age also influences the occurrence of anaplasmosis. The highest prevalence was found in the age of above 3 years (34.19\%), followed in $>2-3$ years (20.51\%) and in 6 months -2 years of age (14.11\%). Anaplasma spp. can cause infections in bovine of all age categories where severity and mortality rate increases with augmentation of animal age (Richey 1984). In divergence with the current study, Khan et al. (2004) and Atif et al. (2012) found adult population more prone to bovine anaplasmosis. Age wise occurrence of anaplasmosis recorded in this study support the report of Chakraborti (2002) who recorded animals over 3 years of age are highly affected by anaplasmosis. Observation of this study also supported by the findings of Kamani et al. (2010) who observed higher prevalence in adult than young cattle. Endemic instability of the study areas might responsible for frequent infections in adult cattle where newborn calves were protected by colostral immunity (Cynthia et al., 2011). It is hypothesized that the strong innate immunity and age resistance of young cattle are responsible for their less vulnerability to tick infestation (Sarkar, 2007) and in such way, leads to less ectoparasitic burden.

Table 2. Age-wise prevalence of anaplasmosis in cattle

\begin{tabular}{|lccc|}
\hline Age group & No. of cattle tested & No. of positive case & Prevalence (\%) \\
\hline 6 months-2 years & 85 & 12 & 14.11 \\
$>2-3$ years & 117 & 24 & 20.51 \\
Above 3 years & 193 & 66 & 34.19 \\
\hline Total & $\mathbf{3 9 5}$ & $\mathbf{1 0 2}$ & $\mathbf{2 5 . 8 2}$ \\
\hline
\end{tabular}

\section{Sex-wise prevalence}

Sex-wise prevalence of anaplasmosis in cattle is shown in table 3. The higher prevalence was reported in female (28.88\%) than male (19.20\%). This result agree with the report of Sarkar (2007) who reported the prevalence of ectoparasites were significantly higher in female than male. The prevalence of hemoprotozoan diseases in female cattle of this investigation showed uniformity with the report of Kamani et al. (2010). Higher prevalence in female cattle possibly due the fact that they were kept longer for breeding and milk production purpose, supplied insufficient feed against their high demand (Kamani et al., 2010) or variation in sample size. 
Table 3. Sex-wise prevalence of anaplasmosis in cattle

\begin{tabular}{|lccc|}
\hline Sex group & No. of cattle tested & No. of positive case & Prevalence (\%) \\
\hline Male & 125 & 24 & 19.20 \\
Female & 270 & 78 & 28.88 \\
\hline Total & $\mathbf{3 9 5}$ & $\mathbf{1 0 2}$ & $\mathbf{2 5 . 8 2}$ \\
\hline
\end{tabular}

\section{Breed-wise prevalence}

Breed-wise prevalence of anaplasmosis in cattle is shown in table 4. The highest prevalence was recorded in HFXL (30.00\%) followed in SL×L (26.80\%), S× L (24.44\%) and local (20.45\%). In the present study, higher prevalence of Anaplasma infections in crossbreed cattle as compared to local cattle was found in agreement with the reports of Radostits et al. (2000). Variation in geoclimatic condition, breed, exposure of vectors and age of the animals might contribute to variable prevalence of hemoprotozoan diseases in the study areas (Muhanguzietal.,2010). Constant exposure of infections and development of immunity against such infections might responsible for lower prevalence in indigenous cattle (Siddiki et al., 2010). On the contrary, more attention in the management of HF crossbred cattle gives less chance of pre exposure of vectors and develop no or less immunity, resulting frequent occurrence of such diseases (Chowdhury et al., 2006; Ananda et al., 2009; Siddiki et al., 2010).

Table 4. Breed-wise prevalence of anaplasmosis in cattle

\begin{tabular}{|llll|}
\hline Breed & No. of cattle tested & No. of positive case & Prevalence (\%) \\
\hline Local & 88 & 18 & 20.45 \\
HF $\times L$ & 120 & 36 & 30.00 \\
SL $\times \mathrm{L}$ & 97 & 26 & 26.80 \\
S $\times L$ & 90 & 22 & 24.44 \\
\hline Total & 395 & 102 & 25.82 \\
\hline
\end{tabular}

Local=Indigenous cattle, HF = Holstein-Friesian, SL = Sahiwal, S = Sindhi, L= Local cattle

Table 5. Season-wise prevalence of anaplasmosis in cattle

\begin{tabular}{|llll|}
\hline Season & No. of cattle tested & No. of positive case & Prevalence (\%) \\
\hline Summer & 120 & 33 & 27.50 \\
Rainy & 176 & 54 & 30.68 \\
Winter & 99 & 15 & 15.15 \\
\hline Total & $\mathbf{3 9 5}$ & $\mathbf{1 0 2}$ & $\mathbf{2 5 . 8 2}$ \\
\hline
\end{tabular}

Summer: March- June; Rainy: July-October and Winter: November-February.

\section{Season-wise prevalence}

Season-wise prevalence of anaplasmosis in cattle in the study area is shown in table 5 . The prevalence of anaplasmosis was ranked the highest in rainy season $(30.68 \%)$ in relation to summer (27.50\%) and winter (15.15\%) season. Observation of rainy season of this research was in accordance with the report of Ananda et al. (2009). Radostits et al. (2000) observed that higher incidence of hemoprotozoan diseases were found soon after peck of tick population depending on temperature, humidity, rainfall etc. which might be accounted for higher prevalence of such infections in rainy season of the study. Lower temperature and humidity of winter months were less favorable for the growth and multiplication of tick vectors which might contribute to lower frequency 
of such diseases in the study population (Muhammad et al., 1999; Zahid et al., 2005). Salih et al. (2008) found the highest number of ticks occur during the rainy season. Sanjay et al. (2007) reported the seasonal prevalence of tick infestation significantly more during the rainy $(24.33 \%)$ and summer seasons $(21.58 \%)$ as compared to the winter season $(4.03 \%)$. This variation may be due to geographical location, climatic condition, reproduction of tick and tick population.

Anaplasma is the tick-borne rikettsial pathogen of cattle which is found endemic in all six populated continents of the world (Futse et al. 2003). Some species of Anaplasma are having zoonotic significance e.g. A. phagocytophilum has been reported as $7.5 \%$ in Egyptian farmers which were in close proximity of the domestic livestock (Ghafar et al. 2011). Anaplasmosis is considered as one of the top ten economically important rickettsial diseases affecting ruminants in India (PDADMAS Annual Report, 2005-06). The situation of ticks and tick-borne diseases like anaplasmosis in animals have been partially documented in Bangladesh by number of authors (Samad, 2000). From the above discussion it is concluded that the prevalence of anaplasmosis in cattle in Sirajganj district of Bangladesh is high which may be due to its agro-ecological and geoclimatic conditions, high density of cattle population, lowland/flood plain based area and high density of tick population. So, for the control and eradication anaplasmosis in cattle population, more attention should be paid towards separation of healthy and infected animals/herds and strictly followed with biosecurity in cattle farm. Reduction of tick population and control of tick's reproduction is the main issue for control of the disease. This should be combined with more government intervention in with awareness program should be undertaken involving stakeholders in the livestock industry as well as consumers to avert public health, veterinary public health and economic losses associated with anaplasmosis.

\section{ACKNOWLEDGEMENT}

The authors are very thankful to Dr. M. Rafiqul Islam, Associate Professor, Department of Anatomy and Histology, BAU, Mymensingh for editing the manuscript. The authors are grateful to Dr. Md. Golzer Hossain, Principal Scientific Officer (PSO), Field Diseases Investigation Laboratory (FDIL), Sirajganj for allowing us to perform our investigation. The authors are also thankful to Upazila Livestock Officer (ULO), Veterinary Surgeon (VS) and Veterinary field Assistant (VFA) of all upazilas in Sirajganj district to help collecting samples.

\section{REFERENCE}

1. Ahmed AKNU, 1976. Blood parasites of domestic animals in Bangladesh. Bangladesh Veterinary Journal, 10: 69-71.

2. Atif FA, MS Khan, F Muhammad and B Ahmad, 2013. Sero-epidemiological study of Anaplasma marginale among cattle. The Journal of Animal and Plant Sciences, 23: 740-744.

3. Ananda KJ, PE Souza and GC Puttalakshmamma, 2009. Prevalence of Haemoprotozoan diseases in crossbred cattle in Banglore north. Veterinary World, 2: 15-16.

4. Arunkumar S and K Nagarajan, 2013. A study on prevalence of Anaplasma marginale infection among cattle population of Kancheepuram and in around Chennai district of Tamil Nadu. International Journal of Food, Agriculture and Veterinary Sciences, 3: 155-157.

5. Chakraborti A, 2002. A Textbook of Preventive Veterinary Medicine, $3^{\text {rd }}$ edition, Kalyani Publishers, New Delhi. pp. 683.

6. Chowdhury S, MA Hossain, SR Barua and S Islam, 2006. Occurrence of common blood parasites of cattle in Sirajgonj Sadar area of Bangladesh. Bangladesh Journal of Veterinary Medicine, 4: 143-145.

7. Cynthia M, MA Kahn, S Line, E Susan and BS Aiello, 2011. Marck Veterinary Manual, Online Ed. Merck Sharp and Dohme Corp, a subsidiary of Merck and Co., Inc. Whitehouse Station, NJ, USA.

8. Futse JE, MW Ueti, DP Knowles and GH Palmer, 2003. Transmission of Anaplasma marginale by Boophilus microplus: retention of vector competence in the absence of vector-pathogen interaction. Journal of Clinical Microbiology, 41: 3829-3834. 
9. Ghafar MW and NA Eltablawy, 2011. Molecular survey of five tick-borne pathogens (Ehrilichia chaffeensis, Ehrlichia ewingii, Anaplasma phagocytophilum, Borrelia burgdorferi sensu lato and Babesia microti) in Egyptian Farmers. Global Veterinaria, 7: 249-255.

10. Khan MQ, A Zahoor, M Jahangir and MA Mirza, 2004. Prevalence of blood parasites in cattle and buffaloes. Pakistan Veterinary Journal, 24: 193-195.

11. Kocan KM, de la Fuente, AA Guglielmone and RD Melendez, 2003. Antigens and alternatives for control of Anaplasma marginale infection in cattle. Clinical Microbiological Review, 16: 698-712.

12. Koshy TJ, G Rajavelu and CM Lalitha CM, 1982. Ecology and binomics of Boophilids of Tamil Nadu. Cheiron, 11: 25-30.

13. Kumar PP and AK Sangwan, 2010. Comparative prevalence of subclinical bovine anaplasmosis under different cattle management systems in Haryana. Haryana Veterinarian, 49 1-5.

14. Kakarsulemankhel JK, 2011. Re-description of existing and description of new record of tick [Hyalomma (Euhyalomma) schulzei] from Pakistan. International Journal of Agriculture and Biology, 13: 689-694.

15. Kamani J, A Sannusi, OK Eqwu, GI Dogo, TJ Tanko, S Kemza, AE Takarki and DS Gbise, 2010. Prevalence and significance of haemoparasitic infections of cattle in North-Central, Nigeria. Vet World, 3: 445-448.

16. Muhanguzi D, K Ikwap, K Picozzi and C Waiswa, 2010. Molecular characterization of anaplasma and ehrlichia species in different cattle breeds and age groups in Mbarara district (Western Uganda). International Journal of Animal and Veterinary Advances, 2: 76-88.

17. Makala LH, P Mangani, K Fujisaki and H Nagasawa, 2003. The current status of major tick borne diseases in Zambia. Veterinary Research, 34: 27-45.

18. Muhammad GM, M Saqib, MZ Athar and MN Khan, 1999. Clinico-epidemiological and therapeutic aspects of bovine theileriosis. Pakistan Veterinary Journal, 19: 64-69.

19. Niyonzema A and HH Kiltz, 1986. Control of ticks and tick-borne diseases in Burundi. Australian Center for International Agricultural Research, 17: 16-17.

20. Razzak A and H Shaikh, 1969. A survey on the prevalence of ticks on cattle in East Pakistan. Pakistan Journal of Veterinary Science, 3: 54-60.

21. Richey EJ, 1984. Management of anaplasmosis in beef cattle. Animal Nutrition for Health, 12: 10-14.

22. Radostits OM, DC Blood and CC Gay, 2000. Veterinary Medicine: A text book of disease of cattle, sheep, pigs, goats and horse. 9th Ed, BaillereTindall Publication, London, pp: 1172-1173, 1289-1290.

23. Samad MA and OP Goutam, 1984. Prevalence of Theileria annulata infection in cattle of Bangladesh. Indian Journal of Parasitology, 7: 61-63.

24. Samad MA, SA Bashar, M Shahidullah and MU Ahmed, 1989. Prevalence of haemoprotozoan parasites in cattle of Bangladesh. Indian Journal of Veterinary Medicine, 13: 50-51.

25. Samad MA, 2000. An overview of livestock research reports published during the twentieth century in Bangladesh. Bangladesh Veterinary Journal, 34: 53 -149.

26. Sanjay K, KD Prasad and AR Deb, 2007. Seasonal prevalence of different ectoparasites infecting cattle and buffaloes. Journal of Research, 16: 159-163.

27. Sarkar M, 2007. Epidemiology and pathology of ectoparasitic infestation in Black Bengal Goats in Bangladesh. M.Sc. thesis. Department of Parasitology, Bangladesh Agricultural University, Mymensingh.

28. Salih DA, II Julia, SM Hassan, AMEI Hussain and F Jongejan, 2008. Preliminary Survey of ticks (Acari: Ixodidae) on Cattle in Central Equatoria State, Southern Sudan. Onderstepoort Journal of Veterinary Research, 75: 47-53.

29. Siddiki AZ, MB Uddin, MB Hasan, MF Hossain, MM Rahman, BC Das, MS Sarker and MA Hossain, 2010. Coproscopic and haematological approaches to determine the prevalence of helminthiasis and protozoan diseases of Red Chittagong Cattle (RCC) breed in Bangladesh. Pakistan Veterinary Journal, 30: 1-6.

30. Talukdar $\mathrm{MH}$ and $\mathrm{MJ}$ Karim, 2001. Subclinical Anaplasma infection in crossbred cattle in Bangladesh. Bangladesh Veterinary Journal, 35: 159-160.

31. Uilenberg G, 1995. International collaborative research: significance of tick-borne hemoparasitic diseases to world animal health. Veterinary Parasitology, 57: 19-41.

32. Zahid IA, M Latif and KB Baloch, 2005. Incidence and treatment of theileriasis and babesiasis. Pakistan Veterinary Journal, 25: 137-139. 